\title{
Metachronous Extrapancreatic Lesions in Autoimmune Pancreatitis
}

\author{
Kensuke Takuma ${ }^{1}$, Terumi Kamisawa ${ }^{1}$, Hajime Anjiki ${ }^{1}$, Naoto Egawa ${ }^{1}$ \\ and Yoshinori Igarashi ${ }^{2}$
}

\begin{abstract}
Objective Autoimmune pancreatitis (AIP) is frequently associated with various extrapancreatic lesions. The distribution and frequency of extrapancreatic lesions preceding or subsequent to AIP are unknown. The aim of this study was to investigate metachronous extrapancreatic lesions of AIP.

Patients and Methods Extrapancreatic lesions were examined clinically, radiologically, and histologically in 56 AIP patients.

Results Extrapancreatic lesions were associated in 25 (45\%) of 56 AIP patients. Twenty-nine extrapancreatic lesions were detected synchronously with AIP in 18 patients, and 18 lesions were detected metachronously in 11 AIP patients. Fourteen patients had more than 2 extrapancreatic lesions. There was no significant difference in serum IgG4 levels between AIP patients with preceding extrapancreatic lesions and synchronous extrapancreatic lesions. Extrapancreatic lesions preceding AIP were sclerosing sialadenitis $(n=8)$, cervical lymphadenopathy $(n=4)$, swelling of the lacrimal glands $(n=2)$, retroperitoneal fibrosis $(n=1)$, and hilar lymphadenopathy $(n=1)$. Retrospective histopathological examination confirmed that these lesions were compatible with IgG4-related sclerosing disease. Steroid therapy was not given for these initial lesions, and AIP occurred 3 to 48 months after these initial lesions. Swelling of the preceding extrapancreatic lesions persisted when AIP occurred. Extrapancreatic lesions subsequent to AIP were retroperitoneal fibrosis $(n=1)$ and systemic lymphadenopathy $(n=1)$, both of which occurred during follow-up of AIP without steroid therapy. All extrapancreatic lesions improved after steroid therapy.

Conclusion Swelling of salivary or lacrimal glands, lymphadenopathy, and retroperitoneal fibrosis can precede AIP. Lymphadenopathy and retroperitoneal fibrosis can occur subsequent to AIP. Recognition of these findings will aid in the correct diagnosis of AIP.
\end{abstract}

Key words: autoimmune pancreatitis, extrapancreatic lesion, sclerosing sialadenitis, retroperitoneal fibrosis, lymphadenopathy

(Inter Med 49: 529-533, 2010)

(DOI: 10.2169/internalmedicine.49.3038)

\section{Introduction}

Autoimmune pancreatitis (AIP), a recently described clinical entity, appears to involve autoimmune mechanisms in its pathogenesis. AIP is characterized clinically by a preponderance of elderly males, jaundice as a frequent initial symptom, and responsiveness to steroid therapy; serologically by elevation of serum IgG or IgG4 levels; radiologically by en- largement of the pancreas and irregular narrowing of the main pancreatic duct; and histopathologically by dense fibrosis with lymphoplasmacytic infiltration in the pancreas $(1,2)$. Other prominent features of this disease involve a variety of extrapancreatic complications (1, 3-5).

We found dense fibrosis with abundant infiltration of $\mathrm{T}$ lymphocytes and IgG4-positive plasma cells and obliterative phlebitis in extrapancreatic lesions associated with AIP, such as sclerosing cholangitis, sclerosing cholecystitis, sclerosing

${ }^{1}$ Department of Internal Medicine, Tokyo Metropolitan Komagome Hospital, Tokyo and ${ }^{2}$ Department of Gastroenterology and Hepatology, Omori Medical Center, Toho University School of Medicine, Tokyo

Received for publication October 19, 2009; Accepted for publication December 10, 2009

Correspondence to Dr. Terumi Kamisawa, kamisawa@cick.jp 
sialadenitis, and retroperitoneal fibrosis. Furthermore, we also found dense infiltration of IgG4-positive plasma cells and $\mathrm{T}$ lymphocytes in various organs of AIP patients, such as the periportal area of the liver, gastric mucosa, colonic mucosa, dermis, lymph nodes, and bone marrow (5-7). Therefore, we proposed the existence of a novel clinicopathological entity, an "IgG4-related sclerosing disease" $(5,6)$. It is a systemic disease characterized by extensive IgG4-positive plasma cell and $\mathrm{T}$ lymphocyte infiltration of various organs. Clinical manifestations are apparent in organs such as the pancreas, bile duct, gallbladder, salivary gland, retroperitoneum, and others where tissue fibrosis with obliterative phlebitis is present on pathology.

Although several papers have dealt with the extrapancreatic lesions of AIP, few studies have focused on the metachronous extrapancreatic lesions of AIP (8). It is important to study patterns of onset of each extrapancreatic lesion. Therefore, we retrospectively examined the clinical features of extrapancreatic lesions preceeding or subsequent to AIP.

\section{Patients and Methods}

We treated 56 AIP patients (45 males and 11 females; mean ( \pm SD) age, 62.8 ( \pm 13.3) years) in Tokyo Metropolitan Komagome Hospital. They were diagnosed as having AIP according to the Asian Diagnostic Criteria for AIP (9): pancreatic enlargement on computed tomography (CT) and ultrasonography (US) $(n=56)$, irregular narrowing of the main pancreatic duct on endoscopic retrograde cholangiopancreatography $(\mathrm{ERCP})(\mathrm{n}=56)$, elevated serum $\operatorname{IgG}(\mathrm{n}=$ 36) and IgG4 $(n=43)$, presence of autoantibodies $(n=22)$, histological findings of lymphoplasmacytic sclerosing pancreatitis $(n=17)$, and steroid responsiveness $(n=39)$. Six patients underwent pancreatoduodenectomy, one patient underwent distal pancreatectomy, and four patients underwent choledochojejunostomy with pancreatic biopsy due to suspicion of pancreatic cancer.

The medical records of these 56 patients were reviewed to identify metachronous and synchronous extrapancreatic lesions. Extrapancreatic lesions of AIP were defined as lesions that were frequently associated with AIP and had IgG4related histological findings similar to those of the pancreas of AIP, such as sclerosing cholangitis, sclerosing cholecystitis, sclerosing sialadenitis, sclerosing dacryoadenitis, retroperitoneal fibrosis, inflammatory pseudotumor and lymphadenopathy $(3,5)$. Extrapancreatic lesions first identified at the diagnosis of AIP were defined as synchronous, and those identified before or after the diagnosis were defined as metachronous. Bile duct lesions were examined by ERCP. The presence of lacrimal and salivary gland lesions was determined by physical examination and CT. The presence of other extrapancreatic lesions was determined by CT. Although stenosis of the lower bile duct was detected in 40 patients, we did not regard segmental stenosis of the intrapancreatic bile duct as an extrapancreatic lesion because it could be influenced by pancreatic enlargement. Swelling of the peripancreatic lymph nodes was observed in almost half of the AIP patients who underwent laparotomy (3). However, to exclude reactive lymphadenopathy, we did not regard them as extrapancreatic lesions. We regarded only distant lymphadenopathy including cervical and hilar lymphadenopathy as extrapancreatic lesions. We excluded 1 sclerosing cholangitis of the intrahepatic bile duct that recurred at the same site during steroid tapering from the subsequent extrapancreatic lesions.

Embedded sections of 5 resected and 6 biopsied extrapancreatic lesions preceding or subsequent to AIP were obtained and immunostained with anti-IgG4 antibody (The Binding Site, Birmingham, UK) using the avidin-biotinperoxidase complex $(\mathrm{ABC})$ method $(6,7)$.

Statistical analysis was performed using chi-squared analysis or Mann-Whitney's U test. P values of less than 0.05 were considered statistically significant.

\section{Results}

Forty-six extrapancreatic lesions were present in 25 (45\%) of 56 AIP patients. Among them, fourteen patients had more than 2 extrapancreatic lesions including synchronous and metachronous lesions. Twenty-nine extrapancreatic lesions, such as sclerosing cholangitis of the intrahepatic bile duct $(n=4)$, sclerosing cholecystitis $(n=14)$, swelling of bilateral salivary glands $(n=5)$, retroperitoneal mass $(n=2)$, inflammatory pseudotumor of the lung $(n=1)$ and cervical lymphadenopathy $(n=3)$, were detected synchronously with AIP in 18 patients. And eighteen lesions were detected metachronously in 11 AIP patients (Table 1).

There was no significant difference in age of diagnosis, gender, and serum IgG4 levels between AIP patients with preceding extrapancreatic lesions and those with synchronous extrapancreatic lesions (Table 2).

Extrapancreatic lesions preceding AIP were swelling of bilateral salivary glands $(n=8)$, cervical lymphadenopathy $(n=4)$, swelling of bilateral lacrimal glands $(n=2)$, retroperitoneal mass $(n=1)$, and hilar lymphadenopathy $(n=1)$. Eight swollen salivary gland lesions, 1 swollen lymph node lesion, and 1 retroperitoneal mass lesion were resected or biopsied on suspicion of salivary gland tumor, malignant lymphoma, and urethral tumor, respectively. Histopathological findings of the salivary glands and the retroperitoneal mass, which were retrospectively examined, were sclerosing sialadenitis and retroperitoneal fibrosis that consisted of dense fibrosis with abundant infiltration of $\mathrm{T}$ lymphocytes and IgG4positive plasma cells and obliterative phlebitis. Retrospective examination of a biopsied cervical lymph node (Case 5) revealed abundant infiltration of IgG4-positive plasma cells. No steroid therapy was performed for these initial lesions, and AIP occurred 3 to 48 months after these initial lesions. Swelling of the preceding extrapancreatic lesions persisted when AIP occurred. Steroid therapy was performed for AIP in 7 patients, in all of whom the preceding extrapancreatic lesions also improved. In Case 8, distal pancreatectomy was 
Table 1. Extrapancreatic Lesions in Patients with Autoimmune Pancreatitis

\begin{tabular}{l|c|c|c|c}
\hline & Preceding & Synchronous & Subsequent & Total \\
\hline $\begin{array}{l}\text { Sclerosing cholangitis of the } \\
\text { intrahepatic bile duct }\end{array}$ & 0 & 4 & 0 & 4 \\
\hline Sclerosing cholecystitis & 0 & 14 & 0 & 14 \\
\hline Sclerosing sialadenitis & 8 & 5 & 0 & 13 \\
\hline Swelling of lacrimal glands & 2 & 0 & 0 & 2 \\
\hline Retroperitoneal fibrosis & 1 & 2 & 1 & 4 \\
\hline $\begin{array}{l}\text { Inflammatory pseudotumor } \\
\text { of the lung }\end{array}$ & 0 & 1 & 0 & 1 \\
\hline Distant lymphadenopathy & 5 & 3 & 1 & 9 \\
\hline
\end{tabular}

Table 2. Comparison of Parameters between Autoimmune Pancreatitis Patients with Synchronous and Preceding Extrapancreatic Lesions

\begin{tabular}{l|c|c|l}
\hline & $\begin{array}{l}\text { Patients with synchronous } \\
\text { extrapancreatic lesions }\end{array}$ & $\begin{array}{l}\text { Patients with preceding } \\
\text { extrapancreatic lesions }\end{array}$ & p value \\
\hline $\begin{array}{l}\text { Age at diagnosis } \\
\text { (years) }\end{array}$ & $67.7 \pm 4.9$ & $64.4 \pm 8.9$ & NS \\
\hline Male/Female & $12 / 2$ & $6 / 1$ & NS \\
\hline Serum IgG4 (mg/dL) & $521.16 \pm 392.9$ & $536.8 \pm 330.7$ & NS* \\
\hline
\end{tabular}

NS, not significant

performed for a mass in the pancreatic tail, and the histological diagnosis was AIP. Steroid therapy was given after resection, and the swelling of the salivary and lacrimal glands improved (Table 3).

Extrapancreatic lesions occurred subsequent to AIP in 2 of 17 patients followed up without steroid therapy. One was retroperitoneal fibrosis occurring 12 months after a by-pass operation for AIP (Case 10), and the other was systemic lymphadenopathy occurring 36 months after pancreatoduodenectomy for AIP (Case 11). In the latter case abundant infiltration of IgG4-positive plasma cells was detected in the biopsied cervical swollen lymph node. Retroperitoneal fibrosis and systemic lymphadenopathy improved after steroid therapy (Table 4).

\section{Discussion}

AIP patients frequently have significantly elevated serum IgG4 levels and various extrapancreatic lesions. Based on histological and immunohistochemical examinations of various organs of AIP patients, we proposed a novel clinicopathological entity, an "IgG4-related sclerosing disease" $(5,6)$. It is a systemic disease, and AIP appears to be a pancreatic lesion reflecting an IgG4-related sclerosing disease. In some cases, only 1 or 2 organs are clinically involved, while in others, 3 or 4 organs are affected (5).

From this point of view, both AIP and the extrapancreatic lesions of AIP may occur randomly. However, in this study, some patterns were recognized in the synchronous and metachronous extrapancreatic lesions of AIP. Sclerosing cholangitis and sclerosing cholecystitis occurred synchronously with AIP. Swelling of bilateral salivary glands was present in 13 AIP patients. Cervical lymphadenopathy was also present in 7 of these patients, as was swelling of bilateral lacrimal glands in 2. Swelling of bilateral salivary glands preceded AIP in 8 patients. They were followed up without steroid therapy, and AIP occurred 3 to 48 months later. Retrospective immunohistochemical examination revealed that the swollen salivary glands were compatible with IgG4-related sclerosing sialadenitis.

Lymphadenopathy in the cervical or hilar lymph nodes, as well as the peripancreatic lymph nodes, is sometimes found in AIP patients. Dense infiltration of IgG4-positive plasma cells was detected in swollen lymph nodes. Cervical lymphadenopathy occurred with swelling of the salivary glands preceding AIP in 4 patients, and malignant lymphoma was suspected. In case 1, sarcoidosis was suspected because the chest X-ray showed bilateral hilar lymphadenopathy 4 years before AIP occurred. Hamano et al also reported 3 AIP patients who were initially diagnosed as having sarcoidosis based on bilateral hilar lymphadenopathy on chest Xray (8). In case 11 , systemic lymphadenopathy appeared 3 years after surgery for AIP. All lymphadenopathy disappeared after steroid therapy. Cheuk et al (10) reported that 2 of 6 cases of unexplained lymphadenopathy associated with elevated serum IgG4/IgG levels and/or increased IgG4positive plasma cells in the lymph nodes developed IgG4related sclerosing disease (sclerosing cholangitis, and scle- 
Table 3. Extrapancreatic Lesions Preceding Autoimmune Pancreatitis

\begin{tabular}{|c|c|c|c|c|c|c|}
\hline Case & $\begin{array}{l}\text { Preceding extrapancreatic } \\
\text { lesions }\end{array}$ & Initial diagnosis & $\begin{array}{l}\text { Initial treatment } \\
\text { (duration) }\end{array}$ & $\begin{array}{l}\text { Extrapancreatic lesions } \\
\text { when AIP occurred }\end{array}$ & Treatment for AIP & Outcome \\
\hline 1 & $\begin{array}{l}\text { Swelling of salivary glands } \\
\text { Hilar lymphadenopathy }\end{array}$ & $\begin{array}{l}\text { Sialadenitis* } \\
\text { s/o sarcoidosis }\end{array}$ & $\begin{array}{l}\text { Follow-up } \\
\text { (48 months) }\end{array}$ & $\begin{array}{l}\text { Swelling } \\
\text { Swelling }\end{array}$ & Steroid & $\begin{array}{l}\text { Improved } \\
\text { Improved }\end{array}$ \\
\hline 2 & $\begin{array}{l}\text { Swelling of salivary glands } \\
\text { Cervical lymphadenopathy }\end{array}$ & $\begin{array}{l}\text { Sialadenitis* } \\
\text { Lymphadenopathy }\end{array}$ & $\begin{array}{l}\text { Follow-up } \\
\text { (18 months) }\end{array}$ & $\begin{array}{l}\text { Swelling } \\
\text { Swelling }\end{array}$ & Steroid & $\begin{array}{l}\text { Improved } \\
\text { Improved }\end{array}$ \\
\hline 3 & Swelling of salivary glands & Sialadenitis** & $\begin{array}{l}\text { Follow-up } \\
\text { (12 months) }\end{array}$ & Swelling & Steroid & Improved \\
\hline 4 & $\begin{array}{l}\text { Swelling of salivary glands } \\
\text { Cervical lymphadenopathy }\end{array}$ & $\begin{array}{l}\text { Sialadenitis* } \\
\text { Lymphadenopathy }\end{array}$ & $\begin{array}{l}\text { Follow-up } \\
\text { (12 months) }\end{array}$ & $\begin{array}{l}\text { Swelling } \\
\text { Swelling }\end{array}$ & Follow-up & $\begin{array}{l}\text { Swelling } \\
\text { Swelling }\end{array}$ \\
\hline 5 & $\begin{array}{l}\text { Swelling of salivary glands } \\
\text { Swelling of lacrimal glands } \\
\text { Cervical lymphadenopathy }\end{array}$ & $\begin{array}{l}\text { Sialadenitis* } \\
\text { Lymphadenopathy** }\end{array}$ & $\begin{array}{l}\text { Follow-up } \\
\text { (10 months) }\end{array}$ & $\begin{array}{l}\text { Swelling } \\
\text { Swelling } \\
\text { Swelling }\end{array}$ & Steroid & $\begin{array}{l}\text { Improved } \\
\text { Improved } \\
\text { improved }\end{array}$ \\
\hline 6 & $\begin{array}{l}\text { Swelling of salivary glands } \\
\text { Cervical lymphadenopathy }\end{array}$ & $\begin{array}{l}\text { Sialadenitis** } \\
\text { Lymphadenopathy }\end{array}$ & $\begin{array}{l}\text { Follow-up } \\
\text { (8 months) }\end{array}$ & Swelling & Steroid & Improve d \\
\hline 7 & Swelling of salivary glands & Sialadenitis** & $\begin{array}{l}\text { Follow-up } \\
\text { (6 months) }\end{array}$ & Swelling & Steroid & Improved \\
\hline 8 & $\begin{array}{l}\text { Swelling of salivary glands } \\
\text { Swelling of lacrimal glands }\end{array}$ & Sialadenitis $* *$ & $\begin{array}{l}\text { Follow-up } \\
\text { (3 months) }\end{array}$ & $\begin{array}{l}\text { Swelling } \\
\text { Swelling }\end{array}$ & Resection & $\begin{array}{l}\text { Improved } \\
\text { with steroid }\end{array}$ \\
\hline 9 & Retroperitoneal mass & $\begin{array}{l}\text { Retroperitoneal } \\
\text { fibrosis* }\end{array}$ & $\begin{array}{l}\text { Resection } \\
\text { (10 months) }\end{array}$ & Urinary stent & Steroid & Improved \\
\hline
\end{tabular}

First diagnosis of extrapancreatic lesions was histologically confirmed by resection* or biopsy**. s/o, suspicious of; AIP, autoimmune pancreatitis

Table 4. Extrapancreatic Lesions Subsequent to Autoimmune Pancreatitis

\begin{tabular}{c|l|l|l|l|l}
\hline Case & $\begin{array}{l}\text { Subsequent extrapancreatic } \\
\text { lesion }\end{array}$ & Treatment for AIP & $\begin{array}{l}\text { Period from AIP to } \\
\text { extrapancreatic lesion }\end{array}$ & $\begin{array}{l}\text { Treatment for } \\
\text { extrapancreatic lesion }\end{array}$ & Outcome \\
\hline 10 & Retroperitoneal fibrosis & By-pass operation & 12 months & Steroid & Improved \\
\hline 11 & Systemic lymphadenopathy** & Resection & 36 months & Steroid & Improved \\
\hline
\end{tabular}

AIP, autoimmune pancreatitis; **, IgG4-related lymphadenopathy was histologically confirmed by biopsy retrospectively.

rosing sialadenitis and dacryoadenitis, respectively), and suggested that these cases may represent the lymphadenopathic form of this systemic disease.

Retroperitoneal fibrosis was present in 4 AIP patients [preceding $(\mathrm{n}=1)$, synchronous $(\mathrm{n}=2)$, and subsequent $(\mathrm{n}=1)$ ]. A preceding retroperitoneal mass was resected due to suspicion of a urethral tumor, and retrospective histological examination revealed that it was retroperitoneal fibrosis with abundant infiltration of IgG4-positive plasma cells. Hamano et al reported 3 cases in which retroperitoneal fibrosis preceded AIP and 3 cases in which retroperitoneal fibrosis occurred subsequent to AIP (8).

All extrapancreatic lesions of AIP showed similar histopathological findings or good responsiveness to steroid therapy. They appear to be clinically involved organs in IgG4related sclerosing disease. However, in our study, the extrapancreatic lesions preceding AIP were sclerosing sialadenitis, swelling of the lacrimal glands, lymphadenopathy, and retroperitoneal fibrosis, while those subsequent to AIP were lymphadenopathy and retroperitoneal fibrosis. It is unclear why the onset period of each lesion was different in IgG4- related systemic disease. AIP occurs most frequently with obstructive jaundice due to associated sclerosing cholangitis (1-5). Compared with AIP, swelling of the salivary or lacrimal glands can be easily noticed even without symptoms. AIP might exist subclinically when preceding salivary or lacrimal gland lesions were diagnosed.

Most of these preceding lesions were resected or biopsied on suspicion of malignant tumors. We should recognize that these lesions are manifestations of IgG4-related sclerosing disease. We should follow them up, being aware of the possibility of AIP. Some AIP cases are still difficult to differentiate from pancreatic cancer, but recognition of a past history of suspicion of salivary gland tumor, malignant lymphoma, sarcoidosis, or urethral tumor will further support the diagnosis of AIP.

In conclusion, swelling of the salivary or lacrimal glands, lymphadenopathy, and retroperitoneal fibrosis can precede AIP. Lymphadenopathy and retroperitoneal fibrosis can occur subsequent to AIP. Recognition of these findings will aid in the correct diagnosis of AIP.

\section{References}


2. Kamisawa T, Okamoto A, Wakabayashi T, Watanabe H, Sawabu N. Appropriate steroid therapy for autoimmune pancreatitis based on long-term outcome. Scand J Gastroenterol 43: 609-613, 2008.

3. Kamisawa T, Egawa N, Nakajima H, Tsuruta K, Okamoto A. Extrapancreatic lesions in autoimmune pancreatitis. J Clin Gastroenterol 39: 904-907, 2005.

4. Ohara H, Nakazawa T, Sano H, et al. Systemic extrapancreatic lesion associated with autoimmune pancreatitis. Pancreas 31: 232237, 2005.

5. Kamisawa T, Okamoto A. Autoimmune pancreatitis: proposal of IgG4-related sclerosing disease. J Gastroenterol 41: 613-625, 2006.

6. Kamisawa T, Funata N, Hayashi Y, et al. A new clinicopathological entity of IgG4-related autoimmune disease. J Gastroenterol $\mathbf{3 8}$ :
982-984, 2003.

7. Kamisawa T, Funata N, Hayashi Y, et al. Close relationship between autoimmune pancreatitis and multifocal fibrosclerosis. Gut 52: 683-687, 2003.

8. Hamano H, Arakura T, Muraki T, Ozaki Y, Kiyosawa K, Kawa S. Prevalence and distribution of extrapancreatic lesions complicating autoimmune pancreatitis. J Gastroenterol 41: 1197-1205, 2006.

9. Otsuki M, Chung JB, Okazaki K, et al. Asian diagnostic criteria for autoimmune pancreatitis: consensus of the Japan-Korea Symposium on Autoimmune Pancreatitis. J Gastroenterol 43: 403-408, 2008.

10. Cheuk W, Yuen HK, Chu SY, Chiu EK, Lam LK, Chan JK. Lymphadenopathy of IgG4-related sclerosing disease. Am J Surg Pathol 32: 671-681, 2008.

(C) 2010 The Japanese Society of Internal Medicine http://www.naika.or.jp/imindex.html 